\title{
EFFECTS OF ARTIFICIAL INTELLIGENCE TECHNOLOGY ON ACCOUNTING PROFESSION AND EDUCATION
}

DOI: 10.17261/Pressacademia.2020.1232

PAP- V.11-2020(4)-p.16-21

\section{Derya Ucoglu}

Istanbul Bilgi University, Faculty of Business, Istanbul, Turkey.

derya.ucoglu@bilgi.edu.tr, ORCID: 0000-0001-5510-3574

To cite this document

Ucoglu, D. (2020). Effects of artificial intelligence technology on accounting profession and education. PressAcademia Procedia (PAP), V.11, p.16-21.

Permanent link to this document: http://doi.org/10.17261/Pressacademia.2020.1232

Copyright: Published by PressAcademia and limited licensed re-use rights only.

\section{ABSTRACT}

Purpose- The increasing use of digitalization and artificial intelligence applications has created an expectation that there will be a decrease in the use of human resources. There is no doubt that these technological developments that allow delivering faster and error -free work wil also affect the accounting and auditing professions and will create essential changes in the roles and expected skills of profe ssional members. Therefore, the purpose of this study is to determine the effects of artificial intelligence technology on accounting profession and education. Methodology- In this study, the accounting master's programs of AACSB accredited universities in the United States were analyzed, and the courses added to the programs to deliver new skills to accountants and auditors were exam ined.

Findings- It is determined that there are many courses offered in the curricula of the programs on business/data analytics, management/accounting information systems, big data, data mining, and similar topics.

Conclusion- For accountancy professionals to get adapted to technological developments quickly and to ensure that the transformation process of the accounting profession is completed in a short period of time, first graduate and then undergraduate program curricula should be updated by adding courses that will provide the necessary skills and competencies. Thus, it will be possible to increase the quality of accounting education by meeting the needs of the accounting professionals with respect to the new technologies such as artificial intelligence.

Keywords: Artificial intelligence, accounting and auditing, accounting education.

JEL Codes: M40, M42.

\section{YAPAYZEKA TEKNOLOJISININ MUHASEBE MESLEĞiNE VE EĞiTiMINE ETKiLERi}

\section{ÖZET}

Amaç- Artan dijitalleşme ve yapay zeka uygulamalarının daha fazla kullanılmaya başlanması, insan kaynağı kullanımının azalması yönünde beklenti yaratmıştır. İşlerin daha hızlı ve hatasız yapılmasını sağlayan söz konusu teknolojik gelişmelerin muhasebe ve denetim mesleklerini de etkileyeceği ve meslek mensuplarının rollerinde ve sahip olmaları gereken becerilerde önemli değişiklikler yaratacağı konusunda şüphe bulunmamaktadır. O nedenle bu çalışmanın amacı, yapay zeka teknolojisinin muhasebe mesleğine ve eğitimine etkilerinin belirlenmesidir. Yöntem- Bu çalışmada Amerika'daki AACSB akredite üniversitelerin muhasebe yüksek lisans programları incelenmiş, muhasebeci ve denetçilere yeni beceriler kazandırmak için programlarına ekledikleri dersler analiz edilmiştir.

Bulgular- Programların içeriğinde iş/veri analitiği, yönetim/muhasebe bilgi sistemleri, büyük veri, veri madenciliği ve benzer konularda birçok ders bulunduğu tespit edilmiştir.

Sonuç- Türkiye' deki meslek mensuplarının teknolojik gelişmelere hızlıca adapta olmasının sağlanması ve muhasebe mesleğinin dönüşüm sürecinin kısa sürede tamamlanabilmesi için üniversitelerin önce lisansüstü, sonra da lisans programlarına gerekli becerileri ve yetkinlikleri kazandıracak dersleri ekleyerek müfredatlarını güncellemeleri önemlidir. Böylece, yapay zeka gibi yeni teknolojilerle ilgili olarak muhasebe profesyonellerinin ihtiyaçlarını karşılayarak, muhasebe eğitiminin kalitesini artırmak mümkün olacaktır.

Anahtar Kelimeler: Yapay zeka, muhasebe ve denetim, muhasebe eğitimi.

JEL Kodları: M40, M42. 


\section{GíRiş}

Teknolojideki hızlı değişim hem iş hayatını hem de muhasebe ve denetim mesleklerini büyük ölçüde etkilemektedir. Teknolojideki güncel ve önemli gelişmelerden biri de yapay zekadır. Yapay zeka (artificial intelligence) ismi bilgisayar bilimcisi John M cCarthy tarafından türetilmiştir ve zekasını kullanarak çeşitli görevleri yerine getiren akıllı bir makine yaratma hedefine sahip olan, bilgisayar biliminin deneysel bir dalıdır (Chukwudi vd., 2018, s.3).

Yapay zeka teknolojisi, muhasebe meslek mensupları ve denetçileri de etkileyerek, gelecekte onların mevcut rollerinin büyük ölçüde değişmesine yol açacaktır. Bu çalışmada da yapay zeka teknolojisinin muhasebe ve denetim mesleklerinde mevcut ve muhtemel kullanım alanları, avantajları ve dezavantajları ile muhasebe eğitimine nasıl yansımaları olabileceği ele alınmıştır.

\section{LITERATÜR INCELEMESI}

Bugünkü muhasebecinin iş tanımı, 20-30 yıl önceki muhasebecilerden oldukça farklıdır. Muhasebecilerin rolü önümüzdeki yıllarda da değişmeye devam edecek ve daha çok mali müşavirlik, iş geliştirme, risk yönetimi ve danışmanlık gibi hizmetlere ağırlık verilecektir. Yapay zeka, muhasebeciler üzerinde yoğun yük yaratan işlerin çoğunu ortadan kaldırarak, muhasebecilerin danışmanlık ve diğer yüksek değerli işlere odaklanmalarına imkan tanıyacaktır. Muhasebecilerin gelecekteki rolü ile ilgili olarak farklı görüşler bulunmakla birlikte, yapay zekanı gerçekleştireceği kayıt tutma ve rapor hazırlama gibi rutin işlemlerin dışında, uzman meslek mensuplarının denetim ve oldukça karmaşık olan mevzuat hükümleri üzerinde çalışmaları beklenmektedir (Greenman, 2017, s.1452). Yapay zeka teknolojisinin karmaşıklı̆ı ve uyg ulama deneyimi eksikliği nedeniyle, yapay zekanın muhasebe alanında kullanımı hala ileri seviyelerde değildir ve bu alanda yapay zeka geliştirilmesi ile ilgili olarak ilerlenecek uzun bir yol bulunmaktadır (Luo, Meng ve cai, 2018, s.852) Yapay zekanın muhasebe ve denetim alanında kullanılması fikri yeni olmamakla beraber bilgi teknolojilerindeki yeni gelişmeler doğrultusunda bu alanlardaki etkilerinin ilerleyen yıllarda çok daha kayda değer olacağı beklenmektedir. Yapay zeka, hem büyük miktarda veriye, hem de verileri işleyebilme gücüne ihtiya ç duymakta olup, günümüzde her ikisi de büyük miktarlarda mevcuttur (Kokina ve Davenport, 2017, s. 115).

Dünyadaki en gelişmiş teknolojilerden biri olan yapay zeka uygulamalarının gelecekte artarak devam etmesi beklenmektedir. Uzmanlar 2030 ylına kadar 800 milyon işin yapay zeka teknolojisi ile gerçekleştirileceğini ve birçok kişinin işsiz kalarak başka alanlara yöneleceklerini düşünmektedir. Palmer Group' un raporuna göre, yapay zeka ve makine öğrenme algoritmaları birçok meslek için risk oluşturmakta ve orta seviye yöneticiler, satış personelleri, gazeteciler, spikerler, yazarlar, muhasebeciler ve doktorlar en çok etkilenebilecek meslek grupları olarak tahmin edilmektedir (Sarıçiçek, 2019, s.1093). Bu nedenle de muhasebecilerin günlük iş aktivitelerine yapay zeka teknolojilerini nasıl adapte edebileceklerini ve yeni veri çeşitlerini nasıl analiz edebileceklerini öğrenmeleri gerekmektedir (Wasny ve Law, 2019, para.18).

Muhasebenin temel işlevleri yapay zeka kullanımı açıından değerlendirildiğinde, kayıt işlevi, belgelerin tarayıııdan geçirilmesi suretiyle otomatik olarak muhasebe kayıtlarına aktarım şeklinde gerçekleşecektir. Sınıflandırma ve özetleme-raporlama zaten mevcut muhasebe yazılımlarıyla gerçekleştirilebilen işlevlerdir. Finansal tabloların çeşitli tekniklerle yapay zeka teknolojisi kullanılarak analiz edilmesi mümkündür. Ancak analiz edilen verilerin analiz sonrası yorumlanması henüz yapay zekalar tarafından gerçekleştirilen bir işlev değildir. Bu nedenle muhasebecilerin gelecekte defter tutma gibi daha geleneksel ve rutin işler yerine, danışmanlık ve mali müşavir lik kon ularında faaliyet göstermeleri beklenmektedir (Gacar, 2019, ss.391-392). Örneğin, Tarmidi ve diğerleri yaptıkları çalışmada, ALIAS (Artificial Intelligence Accounting System) sistemini tanıtmıs ve bu sistem ile bir muhasebe yazılımına muhasebecinin işlemleri girmesi yerine, kayıt sürecinin yapay zeka tarafından yapııması öngörülmüştür. Öncelikle bir dokümanın fotoğrafı veya taranmış hali makine tarafından kodlanmış metne (OKT optik karakter tanıma) dönüştürülecek ve sisteme yüklenecektir. OKT, kaynak dokümanın benzersiz özelliğini tanıyarak veritabanında saklanan geçmiş verilerle karşılaştıracaktır. Yapay zekanın makine öğrenmesi özelliği yardımıyla işlemin tanımı ve doğası (gelir, gider, vb.) otomatik olarak belirlenecek ve işlemleri kaydetmek için ilgili hesaplar seçilecektir. Böylece finansal işlemlerin daha sağlıklı bir şekilde kayıtlara aktarılması ve finansal bilginin daha iyi yönetilmesi söz konusu olacaktır (Tarmidi vd., 2018, ss.1117-1118). Dolayısıyla Tarmidi ve diğerlerinin tanıttıkları örnek sistem gibi sistemler dikkate alındı̆ı̆nda, önümüzdeki yıllarda muhasebecilerin daha çok büyük verileri analiz edebilme, stratejik düşünme ve akı yürütme gibi niteliklere sahip olmalarının fayda sağlayacağı öngörülmektedir (Gacar, 2019, ss. 391-392).

Yapay zeka, muhasebe alanında zaten belirli ölçülerde mevcut olup, gittikçe manuel veri girişine bağımlılı̆ı azaltma kta, meslek mensuplarına ve işletmelere birçok fayda sağlamaktadır. Denetçiler çoğunlukla test prosedürleri uygularken, yapay zeka sayesinde örneklem seçme yerine bütün işlemleri analiz etmeleri mümkündür. Böylece veri analizi kalite ve miktar açııından artacaktır. Ayrıca yapay zeka ile insanlara kıyasla verilerdeki daha karmaşık kalıplar ve dizaynlar tespit edilebilir. Yapay zeka, kullandığı geri bildirim döngüleri ile hatalarından veya yeni vakalardan anında ve otomatik olarak öğrenebilir ve zamanla daha akıllı hale gelebilir. Hiçbir zaman unutmaz ve kurumsal belleğini devamlı olarak geliştirir ve derinleştirir. İnsanları etkileyen biyolojik ve fizyolojik dalgalanmalardan etkilenmediği için, yapay zeka insanlara göre çok daha tutarlı bir karar vericidir. Muhasebe kayıtları manuel yapııırken, insan kaynaklı hataların fark edilemediği durumlar olabiliyorken, yapay zeka hataları hemen tespit ederek kayıtların devamlı doğru olmasını sağlayabilir. Böylece muhasebeciler manuel veri girişi ve kontrolü gibi sıkıcı işlerle uğraşmak yerine, insani bir dokunuş gerektiren işlere daha fazla emek harcayabilirler. Ayrıca bir muhasebecinin uzun zaman harcayarak analiz edebileceği büyük ölçekli veriler yapay zeka ile çok kısa sürede işlenebilir (Wasny ve Law, 2019, para.7-16).

Yapay zeka, insan yargısı ve bilişsel becerilerini taklit etmek için programlanmış ve çevresel işaretleri almak için tasarlanabilen bir teknoloji olduğundan, işaretlere dayanarak karar verme, tahmin etme veya harekete geçme risklerini değerlendirebilir. Diğer yazılımlardan farklı ol arak yapay zeka sistemleri verilerden öğrenme kapasitesine sahiptir ve yeni verilere maruz kaldıkça, bir insan tarafından programlanmadan kendi kendine gelişebilir (Munoko, Brown-Liburd ve Vasarhelyi, 2020, s.2) Bilişim teknolojilerindeki gelişmeler doğrultusunda büyük muhasebe ve denetim firmalarının çoğu, entegre denetim otomasyon sistemlerinin bir parçası olarak yapay zeka kullanımını başlatmıştır. Da ha önceden öngörüldüğü şekilde, Elektronik Veri Değişimi (EDI), Elektronik Dosya Transferi (EFT) ve görüntü işleme gibi bilgi ve iletişim teknolojileri (ICT) cihazları yavaş yavaş geleneksel denetim şekillerinin yerini alarak, tüm denetim sürecini tamamen değiştirmektedir (Omoteso, 2012, s.8490). Dolayısıyla, yapay zeka karar verme sürecinin ayrılmaz bir parçası haline gelmekte ve denetim dahil olmak üzere modern işlerin ve mesleklerin hem teknik hem de idari süreçleri için geliştirilmeye ve uygulanmaya devam etmektedir (Serçemeli, 2018, s.371). 
Muhasebe mesleğinin yanında, denetim alanında da yapay zeka uygulamaları yoğunlukla yer almaya başlamıştır. Denetimin kendine has doğası, yapay zeka kullanımına imkan sağlayan bir niteliktedir. Denetim ve güvence hizmetleri, yapılandırımamış ve yarı yapılandırılmış ancak sıklıkla tekrar eden kararlarla ilgili ve eksik bilgi ve belirsizlikle ilgili risk değerlendirmelerini içerir. Değişik araştırmalarda, denetim faaliyetleri için kullanılan karar yardımcıları hakkında denetçi algıları incelenmiştir. Bu araştırmaların sonuçları, faaliyetlerin ne kadar karmaşık olduğuna bakılmaksızın, denetçilerin karar yardımcılarına veya bilgi tabanlı (uzman) sistemlere kıyasla bilgi işleme sürecinin insanlar tarafından yapılmasını tercih ettiklerini göstermektedir. Ancak günümüzde, insan uzmanların sınırlamaları olduğu fikri de büyük ölçüde kabul görmektedir (Baldwin, Brown ve Trinkle, 2006, s.79) İşletmeler, gerçek zamanlı stok sayımlarından, satış noktalarından gönderi takip bilgilerine kadar sürekli olarak büyük miktarlarda veri üretmekte ve toplamaktadır. Ayrıca, sosyal medya ve haber kaynaklarıgibi dışsal kaynaklardan elde edilen bilgiler de kolayca erişilebilir ve analiz edilebilir durumdadır. Aslında, denetim mesleğini daha ileriye taşıması beklenen şey de yapay zekanın bu tür büyük verilere (big data) uygulanmasıdır. Bu kadar büyük veri tabanları ile çalışılırken, geleneksel denetim prosedürleri daha az etkili ve daha az etkin hale gelmekte olduğundan, denetimlerin nasıl yürütülmesi gerektiğinin yeniden şekillendirilmesi uygun olacaktır. Sosyal bilimler literatüründeki birçok çalışma, insanların çoklu kaynaklardan yüksek miktarda bilgi toplanmasını ve birleştirilmesini gerektiren karmaşık görevlerde iyi performans gösteremediğini tespit etmiştir. Muhasebe ve denetim alanında yapılan çalışmalarda da insanların büyük miktarda bilgiye maruz kalmasının artan belirsizlik, aşırı bilgi yüklemesi, ihtiyaca uygun bilginin belirlenmesinde zorluklar yaşanması ve sonuç olarak denetimle ilgili yeterli olmayan mesleki yargı kullanımına yol açabileceği görülmüştür. Bu sorun, büyük verinin yapılandırılmamış doğası ve iç kontrol prosedürlerinin değerlendirilmesi gibi belirli dene tim görevlerinin içerdiği yüksek düzeyde karmaşıklık ile daha da artmaktadır. Dolayısıyla, yeni metodolojiler denetçilerin yukarıda belirtilen sınırlamaları aşmalarına yardımcı olabilir (Issa, Sun ve Vasarhelyi, 2016 ,s.9). Yapay zeka, denetim sürecinde işlem veri setindeki istisnaların ve tutarsızlıkların kolayca belirlenmesinde ve denetçiler tarafından manuel olarak incelenen istisnaların yapay zekanın öğrenme fonksiyonu sayesinde otomatik olarak ayrıştırılmasında kullanılabilir (Shimamoto, 2018, 15).

Ancak denetim alanında yapay zeka kullanımının henüz yeterince yaygınlaşmasınıengelleyen önemli nedenlerden biri işletmelerin birbirinden farklı ve entegre olmayan muhasebe yazılımları kullanıyor olmasıdır. Entegre programların olmaması, yapay zekanın denetimle ilgili kontrol alanını sınırlandırmaktadır. Buna ek olarak, denetlenecek firmaların bir kısmında alanında uzman bilgi işlem personelinin bulunmaması veya işletmelerin dışardan bilgi işlem hizmeti alıyor olmaları, yapay zeka ile denetim yapılmasını engelleyen veya denetim sürecini yavaşlatan bir diğer husustur. İşletmelerin faaliyet gösterdiği sektörlerin farklı olması, veri gir işinde farklı yöntemler veya teknikler kullanmaları, yapay zekanın verileri anlamlandırmasına engel olmakta veya sürecin tamamlanma süresini uzatmaktadır (Taş ve Mert, 2019, s.67). Denetimde yapay zeka kullanımının birçok faydası bulunmakla birlikte, yeni teknolojilerin faydalarının yanında, yarattıkları yeni risklerin de değerlendirilmesi gerekmektedir. Yapay zeka, zaman tasarrufu sağlayan çözümler üretmesine rağmen, insanların sahip olduğu der inlemesine akıl yürütme yeteneği ve duyguları ifade edebilme özelliklerine sahip değildir. Ayrıca denetçilik profesyonel mesleğinin bir gereği olan mesleki yargı ve şüpheciliğe sahip olma gibi bazı özellikler de insanların daha üstün olmasını sağlamaktadır. Yapay zeka teknolojisin in, ekonomiyi ve nitelikli işçi piyasasını negatif olarak etkilemesi beklenmekte olup muhasebe ve denetim profesyonellerinin bir kısmının işlerini kaybetmeleri mümkündür. Bazı araştırmacılar da işlerini kaybedenler olabileceğini, ancak yeni iş olanaklarının ortaya çıkmasının da muhtem el olduğunu savunmaktadır (Bizarro ve Dorian, 2017, s.24).

Yapay zeka destekli bilgi sistemlerinin denetimde kullanılması ile ilgili tartışmalar daha çok verilerin toplanması ve kullanılabilir bir formata dönüştürülmesi konusundadır. Yapay zeka kullanımının, hem denetçilerin denetim planlarına hem de veriyi nasıl analiz ettiklerine yansıması beklenmektedir. Henüz yapay zekanın karar verme yönü tamamen gelişmemişse de, verinin toplanması ve organize edilmesi gibi monoton işlerin yapay zeka tarafından yapılması, denetçilere karar verme ve mesleki yargı kullanma konularında zamanlarını daha verimli kullanma imkanı tanımaktadır. Yapay zeka, incelenmesi gereken çok fazla verinin olduğu durumlarda denetçiler tarafından önemlilik ve risk analizi, kanıtların değerlendirilmesi, denetim planlaması, iç kontrol sistemi değerlendirmesi, belirli hesapların analiz edilmesi, bir görüş seçilmesi ve rapor yazılması konularında kullanılabilir (Meskovic vd., 2018, s.8). Denetimde yapay zeka uygulamalarının kullanımı, denetimin verimliliğ ini önemli ölçüde artırabilecektir. Sürekli olarak daha fazla veri üretilip toplandıkça ve daha sık denetim yapılması talebi arttıkça, yapay zeka uygulamalarının devreye alınması süreci hızlanacaktır (Issa, Sun ve Vasarhelyi, 2016, s.9). İşletmeler ve denetçiler yapay zekaya giderek daha fazla güvendiklerinden, yapabilecekleri bazı temel varsayımlar vardır. Birinci varsayım, bu sistemlerin daima doğru olduğudur; ikinci bir varsayım, yapay zeka sistemlerinin her zaman istenen kısıtlamalar içinde hareket edeceğidir; üçüncü varsayım ise yapay zekanın istenen kısıtlamalardan sapması durumunda, bu durumun saptanabilir ve düzeltilebilir olacağıdır. Ancak bu varsayımlar her zaman geçer li olmayabilir ve bu da etik, yasal ve ekonomik sonuçlara yol açabilir (Munoko, Brown-Liburd ve Vasarhelyi, 2020, s.2). Yapay zeka teknolojisi muhasebe ve denetim alanlarında kullanılırken, bu hususların da değerlendirilmesi önemlidir.

\section{YÖNTEM}

Yapay zeka teknolojileri, muhasebe mesleğinin ve muhasebecilerin rollerini etkilemekte olduğundan, muhasebe eğitimcilerinin akıllı teknolojiler ve onların iş uygulamaları ile ilgili yeni ve gerekli beceriler ve yetkinlikler geliştirecek bir eğitim sistemi üzerinde çalışmaları gerekmektedir. Bu nedenle muhasebe müfredatlarının gözden geçirilerek mezunların başarılı bir kariyere hazırlanması için gere kli hazırlıkların yapılması önceliklidir (Stancheva-Todorova, 2018, s.139). Bazı uzmanlara göre, yakın gelecekte, becerilerde \%35 oranında farklılık olması beklenmektedir. Artık hem mesleklerin hem de bu mesleklerle ilgili olarak üniversite mezunlarının ihtiyaç duyacakları beceriler oldukça farklı olacaktır. Ayrıca yapay zekanın ilk başta iş imkanlarında ve istihdam edilen muhasebeci sayısında azalmaya yol açacağına, ancak uzun vadede daha geniş resme bakıldığında etkisinin çok olumsuz olmayacağı ve okullardaki ve üniversitelerdeki eğitimin çok yönlülüğünün artmasına katkıda bulunacağı düşünülmektedir (Griffin, 2019, para.9-12).

Yapay zekanın muhasebe ve denetim alanındaki mevcut kullanımı, gelecekte bu kullanım alanlarının daha da genişleyeceği, bu ka psamda muhasebecilerin ve denetçilerin alacağı yeni roller ve bunların gerektirdiği yeni beceriler dikkate alınarak, Türkiye' deki üniversitelerin de en azından lisansüstü muhasebe müfredatlarında büyük veri, karar destek sistemleri, bilgi sistemleri, iş analitiği ve veri maden ciliği gibi alanlarda yetkinlik kazandıracak derslere yer verecek şekilde müfredatlarını güncellemeleri önem kazanacaktır. Yapay zekanın muhasebe müfredatlarına dahil edilmesi konusunda önerilen aşamalarıyapay zeka entegrasyonu ihtiyacının tanımlanması, Fakültenin yapay zeka ile 
ilgili konularda bilgi sahibi olması, yapay zeka ile ilgili konuların müfredata dahil edilmesi ve öğrencilerin yapay zeka ve yapay zeka ile ilişkili konularda bilgi edinmesidir. İlk aşama, muhasebecilerin gelecekte yapay zekaya aşina olması gerekliliğinden hareket ederek, üniversitelerdeki muhasebe eğitimi müfredatına yapay zeka ile ilişkili konuların entegrasyon ihtiyacının tanımlanmasıdır. İkinci aşama ise, Fakültenin yapay zeka ve ilişkili konularda bilgi sahibi olmasıdır. Ancak bu aşamada muhasebe alanındaki öğretim elemanlarının söz konusu alan larla ilgili yeterli bilgi sahibi olmamasının bir engel oluşturması ihtimali mevcuttur. Üçüncü aşamada, konuya hakim ve bilgili öğretim elemanları ve bölümler, muhasebe ve denetim mesleklerinde yapay zeka teknolojileri kullanımının gerektireceği müfredat değişikliklerini en uygun şekilde uygulamalıdır. Son aşama da müfredatta yapılan değişikliklerin öğrencilere en iyi şekilde aktarılarak, öğrencilerin yapay zeka bi lgisi ve yapay zeka kullanımının gerektireceği yeni becerileri edinmesinin sağlanmasıdır (Baldwin-Morgan, 1995, s.217-218).

Bu çalışmada, yapay zekanın muhasebe eğitimine etkisinin genel olarak tespiti için ABD'deki muhasebe yüksek lisans programlarının müfredatları incelenmiştir. Söz konusu inceleme için, işletme ve muhasebe programları ile ilgili olarak kredibilitesi ve bilinirliği en fazla ve en katı süreçlere sahip olan akreditasyon kurumu olan AACSB (The Association to Advance Collegiate Schools of Business) resmi we b sitesindeki veriler kullanılmıştır. ABD’de “i̇şletme ve Muhasebe” akreditasyonu almış olan 179 üniversitenin resmi web siteleri incelenmiştir.

\section{BULGULAR}

Üniversitelerin bir kısmının Muhasebe alanında yüksek lisans programı olmadığı ve bir kısmının da muhasebe yüksek lisans progr amları olmasına rağmen web sitelerinden program müfredatlarına ve ders bilgilerine ulaşma imkanı bulunmadığı (detaylı bilgiye erişim için ad/soyad, email, telefon gibi kişisel bilgiler talep edilmekte) için, toplam 142 yüksek lisans programı ile ilgili veriye ulaşılabilmiş tir. Programların isimleri ile ilgili bilgiler aşağıdaki tabloda yer almaktadır:

Tablo 1: AACSB Akreditasyonlu Amerikan Üniversitelerinin Muhasebe Alanındaki Yüksek Lisans Program İsimleri

\begin{tabular}{|l|c|l|c|}
\hline Yüksek Lisans Program Adı & Frekansı & Yüksek Lisans Program Adı & Frekansı \\
\hline Accountancy & 66 & Accountancy - Data and Analytics & 1 \\
\hline Accounting & 66 & Accounting \& Business Advisory Services & 1 \\
\hline Professional Accountancy & 3 & Accounting and Information Systems & 1 \\
\hline Professional Accounting & 3 & Management-Accounting & 1 \\
\hline
\end{tabular}

Yapılan içerik analizi sonuçları doğrultusunda, 142 yüksek lisans programının 29 tanesinde iş/veri analitiği, yönetim/muhasebe bilgi sistemleri, büyük veri, veri madenciliği veya benzer konularda derslere hiç yer verilmemiş olduğu, klasik muhasebe yüksek lisans müfredat derslerinin (finansal raporlama, maliyet muhasebesi, denetim, vergi vb.) mevcut olduğu tespit edilmiştir. Geriye kalan 113 programda yer alan zorunlu ve seçmeli dersler kategorize edilerek, aşağıdaki özet tablo hazırlanmıştır.

Tablo 2: AACSB Akreditasyonlu Amerikan Üniversitelerinin Müfredatlarında Yeni Becerilerin Edinilmesine ilişkin Olarak Yer Alan Dersler

\begin{tabular}{|l|l|l|l|l|l|}
\hline İş/Veri Analitiği & Yönetim/Muhasebe/ Denetim Bilgi Sistemleri & Veri Madenciliği & Büyük Veri & Diğer & TOPLAM \\
\hline 83 & 62 & 10 & 6 & 50 & $\mathbf{2 1 1}$ \\
\hline
\end{tabular}

Programların çoğunda hem iş/veri analitiği, hem de yönetim/muhasebe/denetim bilgi sistemleri ile ilgili derslerin yer aldığı görülmektedir. Veri madenciliği ve büyük veri ile ilgili olarak sınırlı sayıda ders sunulmaktadır. Bu derslerin dışında, veri ve veritabanı yönetimi, sistem analizi ve dizaynı, gelişmiş yapay zeka sistemleri, denetim teknolojilerindeki yenilikler, makine öğrenmesi, veri ile karar verme, muhasebe ve denetimde yeni geliştirilen teknolojiler, yönetim kararları için bilgi analizi gibi birbirinden farklı dersler sunulduğu tespit edilmiştir. Programların sunduğu söz konusu derslerin bir kısmının muhasebe programının kendi koduyla açıldığı, bir kısmının ise üniversitelerin çoğunda bulunan İş Analitiği yüksek lisans program derslerinden beslendiği anlaşılmıştır. Üniversitelerin bir kısmında, alt uzmanlık alanları bulunduğu, bu alanların ağırlıkla finansal raporlama/muhasebe, denetim, vergi ve iş analitiği oldukları görülmüştür. İş analitiği uzmanlığının artık birçok programda yer bulduğu ve hatta 2 tane programın isminin de "Muhasebe - Veri ve Analitik" ve "Muhasebe ve Bilgi Sistemleri" şeklinde oluşturulduğu dikkat çekmektedir.

Tablo 2' de yer alan toplam 211 dersin programlara dağılımı analiz edildiğinde, 52 tane programda yalnızca 1 ders, 30 tane programda 2'şer ders, 25 tane programda 3'er ders ve 6 tane programda da 4'er ders sunulduğu görülmüştür. Öğrencilerine 3 veya daha fazla der s sunan üniversitelerin, genelde iş analitiği alt uzmanlık alanlarının bulunduğu veya programın zaten muhasebe ve analitik/bilgi sistemleri adına sahip olduğu tespit edilmiştir. Genel olarak değerlendirildiğinde, Amerika'daki AACSB akreditasyonlu üniversitelerin çoğunun yapay zeka teknolojilerinin getirdiği yeni roller ve beceri ihtiyaçları doğrultusunda programlarını halihazırda güncellemiş oldukları belirlenmiştir. Türkiye' de ise Veri Bilimi, İş Analitiği, Veri Analitiği, Veri Yönetimi, Veri Mühendisliği gibi isimlerle, çoğu vakıf ünivers itelerinde açılmış olan, yaklaşık 15 tane yüksek lisans programı bulunmaktadır. Amerika ile karşılaştırıldığında, henüz bu alanın Türkiye'de yeni ve gelişmekte olduğunu söylemek yanlış olmayacaktır. Muhasebe ve denetim alanlarında Türkiye' de toplam 78 tane (13 vakıf ve 34 devlet üniversitesinde) yüksek lisans programı mevcut olup, bu programların 18 tanesinde "Muhasebe ve Denetimde Teknoloji Uygulamaları" ile ilgili dersler ve 21 tanesinde "Muhasebe Bilgi Sistemi" ile ilgili dersler mevcut olup, bunlar dışında yapay zeka teknolojilerine ilişkin becerilerin edindirilmesine yönelik zorunlu ders veya seçmeli ders (program seçmeli ders havuzunda) bulunmamaktadır. Türkiye' de iş ve veri analitiği alanlarındaki çalışmaların ve yüksek lisans programlarının daha da yaygınlaşması ile birlikte, söz konusu alandaki derslerin muhasebe ve denetim yüksek lisans programlarına entegre edilmesinin öneminin daha da anlaşılacağı düşünülmektedir. 


\section{SONUÇ VEÖNERILER}

Birçok alanda uygulama bulan yapay zeka teknolojisi, muhasebe ve denetim mesleklerinde de önemli etkilere yol açmaktadır. Örneğin bir denetçi banka kredileri ile ilgili faiz hesaplamalarının doğruluğunu kontrol etmek için 1.000 banka kredisinden 100 tanesini seçip hesaplama yaparken ve onlarda sorun tespit edemediği durumda kar veya zarar tablosuna yansıtılan finansman giderinin doğru olduğunu kabul ederken, artık yapay zeka teknolojileri sayesinde örneklem belirlemeye gerek olmadan 1.000 kredinin hepsi için faiz hesaplama doğrulamasının yapılarak finansman giderinin finansal tablolara doğru yansıtılıp yansıtılmadığının kesin olarak belirlenmesi mümkündür. Artık muhas ebeciler ve denetçiler hazırlayacakları raporlara birçok farklı kaynaktan bilgi sağlamaktadırlar. Farklı kaynaklardan gelen bilgile rin tek bir kullanılabilir raporda toplanması için, veri temizleme ve analiz etme becerilerine sahip olunması gerekmektedir (Kinonen, 2019, ss.34-35).

Teknolojik gelişmelerle birlikte, muhasebecilik mesleği defter tutma ve beyanname verme gibi rutin fonksiyonlarından uzaklaşmaktadır. Şu anda meslek mensuplarının gerçekleştirmekte olduğu birçok işlem, yakın zamanda tamamen yapay zeka uygulamaları tarafından yapılır hale gelecektir. Bu doğrultuda muhasebe meslek mensupları ve denetçilere sahip olmaları gereken yeni analitik becerilerin kazandırılması konusunda çağın gerekliliklerinin yakalanması çok önemlidir.

Henüz yapay zeka teknolojisinin Türkiye'deki muhasebe ve denetim mesleğine yansımaları sınırlıyken, önce lisansüstü eğitim, sonrasında da lisans eğitim müfredatlarına meslek mensuplarının sahip olmaları gereken yeni beceriler ve yetkinlikler doğrultusunda dersler (iş analitiği, veri madenciliği, büyük veri yönetimi vb.) eklenerek müfredatların güncellenmesi, meslek mensuplarının analitik becerilerini artırarak, mesleğin teknolojik gelişmelerin gerisinde kalmasını engelleyecektir.

\section{KAYNAKÇA}

Baldwin-Morgan, A. A. (1995), “Integrating Artificial Intelligence into the Accounting Curriculum”, Accounting Education, 4(3), 217-229.

Bizarro, P. A. ve Dorian, M. (2017), “Artificial Intelligence: The Future of Auditing”, Internal Auditing, 5(1), 21-26.

Baldwin, A. A., Brown, C. E. ve Trinkle, B. S. (2006), “Opportunities for Artificial Intelligence Development in the Accounting Domain: The Case for Auditing", Intelligent Systems in Accounting, Finance and Management, 14(3), 77-86.

Chukwudi, O. L., Echefu, S. C., Boniface, U. U. ve Victoria, C. N. (2018), "Effect of Artificial Intelligence on the Performance of Accounting Operations among Accounting Firms in South East Nigeria", Asian Journal of Economics, Business and Accounting, 7(2), 1-11.

Gacar, A. (2019), "Yapay Zekâ ve Yapay Zekânın Muhasebe Mesleğine Olan Etkileri: Türkiye'ye Yönelik Fırsat ve Tehditler", Balkan Sosyal Bilimler Dergisi, 8, 389-394.

Greenman, C. (2017), "Exploring the Impact of Artificial Intelligence on the Accounting Profession", Journal of Research in Business, Economics and Management (JRBEM), 8(3), 1451-1454.

Griffin, O. (2019), "How artificial intelligence will impact accounting", https://www.icaew.com/technical/technology/artifici alintelligence/artificial-intelligence-articles/how-artificial-intelligence-will-impact-accounting (Erişim Tarihi: 01.05.2020)

Issa, H., Sun, T. ve Vasarhelyi, M. A. (2016), "Research Ideas for Artificial Intelligence in Auditing:The Formalization of Audit andWorkforce Supplementation", Journal of Emerging Technologies in Accounting, 13(2), 1-20.

Kinonen, J. (2019), "The Accountant of The Future - Data Analytics and Artificial Intelligence are Redefining the Profession and McCombs is Keeping Pace", https://www.mccombs.utexas.edu/ /media/Files/MSB/Program\%20MPA/McCombsMagazine_Fall19_DataAnalytics.pdf (Erişim Tarihi: 14.05.2020)

Kokina, J. ve Davenport, T. H. (2017), "The Emergence of Artificial Intelligence: How Automation is Changing Auditing", Journal of Emerging Technologies in Accounting, 14(1), 115-122.

Luo, J., Meng, Q. ve Cai, Y. (2018), "Analysis of the Impact of Artificial Intelligence Application on the Development of Accounting Industry", Open Journal of Business and Management, 6(1), 850-856.

Meskovic, E., Garrison, M., Ghezal, S. ve Chen, Y. (2018), “Artificial Intelligence: Trends in Business and Implications for the Accounting Profession", Internal Auditing, 5, 5-11.

Munoko, I., Brown-Liburd, H. L. ve Vasarhelyi, M. (2020), "The Ethical Implications of Using Artificial Intelligence in Auditing", Journal of Business Ethics, 1-26.

Omoteso, K. (2012), "The application of artificial intelligence in auditing: Looking back to the future", Expert Systems with Applications, 39(9), 8490-8495.

Sarıçiçek, R. (2019), "Muhasebe Alanındaki Dönüşüm ve Yapay Zeka”, 2. Uluslararası İnsan ve Toplum Bilimleri Araştırmaları Kongresi, Bandırma, 1092-1099.

Serçemeli, M. (2018), “Muhasebe ve Denetim Mesleklerinin Dijital Dönüşümünde Yapay Zeka”, Turkish Studies, 13(30), 369-386.

Shimamoto, D. C. (Winter 2018/2019), “Is Artificial Intelligence a Threat to Government Accountants and Auditors?”, Journal of Government Financial Management, 67(4), 12-16. 
Stancheva-Todorova, E. P. (2018), “How Artificial Intelligence is Challenging Accounting Profession”, Economy \& Business, 12(1), $126-141$.

Tarmidi, M. B., Rozalan, A. H. A., Rasli, M. A. M., Roni, R. A. ve Alizan, N. K. S. (2018), "Artificial Intelligence Accounting Sys tem (ALIAS)”, Global Business and Management Research: An International Journal, 10(3), 1116-1119.

Taş, O. ve Mert, H. (2019), “Denetimde Yapay Zeka Uygulaması”, PressAcademia Procedia (Global Business Research Congress), 9, $65-68$.

Wasny, G. ve Law, M. (2019), "How artificial intelligence will change the way accountants work", https://www.accountingtoday.com/opinion/how-ai-will-change-the-way-accountants-work (Erişim Tarihi: 10.04.2020) 